\title{
Crown-down preflaring in the determination of the first apical file
}

\author{
Luiz Fernando Machado Silveira(a) \\ Carina Folgearini Silveira ${ }^{(b)}$ \\ Luis Antônio Suita de Castro(c) \\ João Batista César Neto(d) \\ Josué Martos(e)
}

\footnotetext{
(a) $\mathrm{PhD}$, Associate Professor, Department of Clinics; (b)Graduate Student; (e)PhD, Adjunct Professor, Department of Clinics - School of Dentistry, Federal University of Pelotas, Pelotas, RS, Brazil.

(c) MSc, EMBRAPA-CPACT; Laboratory of Immunology and Microscopy, Pelotas, RS, Brazil.

(d) $\mathrm{PhD}$, Professor, Department of Stomatology, School of Dentistry, University of São Paulo (USP), São Paulo, SP, Brazil.
}

Corresponding author:

Luiz Fernando Machado Silveira

Rua Santa Cruz, 2434/602

Pelotas - RS - Brazil

CEP: 96015-710

E-mail:Ifms1960@gmail.com

Received for publication on Jun 23, 2009 Accepted for publication on Dec 17, 2009
Abstract: In this study, scanning electron microscopy (SEM) was used to evaluate the adaptation of the first apical file after preflaring in mesiobuccal $(\mathrm{MB})$ and mesiolingual (ML) canals of mandibular molars considering the tactile sensibility as a reference. The mesial canals $(\mathrm{n}=22)$ of human mandibular molar teeth were used, and the first instrument to bind to the working length was determined after preflaring and crowndown shaping. Digital images of the root apex were acquired and a single examiner determined the contact of the file with the walls using Image J software. The results showed that the file was in contact in $47.83 \%$ and $31.71 \%$ in the $\mathrm{MB}$ and $\mathrm{ML}$ canals, respectively. When the apexes are fused, the average was $40.03 \%$. A descriptive analysis showed that the first apical file did not touch all dentin walls in any of the samples.

Descriptors: Molar / anatomy \& histology; Root canal preparation; Root canal therapy; Microscopy, electron, scanning; Endodontics.

\section{Introduction}

The success of endodontic treatment demands knowledge of the root canal system. However, bidimensional radiographic images do not represent anatomical conditions. Most canals do not communicate with periodontal tissue precisely at the root apex, and the apical foramen often does not have a round shape. ${ }^{1}$ Morphologic analyses have shown that canals are oval-shaped or irregular in the apical third and present their largest diameter at the buccolingual aspect..$^{2,3,4}$

This concept is confirmed by the fact that the first file that clinically binds to the apex is smaller than the anatomical diameter of the apical foramen. ${ }^{5}$ Weine $^{6}$ (1989) proposed that the apical enlargement must be three sizes larger than the first file that bound at the working length. ${ }^{6}$ However, if the apical diameter corresponds to $0.25 \mathrm{~mm}$ in its smallest extension and $0.50 \mathrm{~mm}$ in its largest extension, binding will occur with instrument \#25, and enlargement will be achieved with instrument \#40 without touching the whole perimeter of the apical foramen. Baugh and Wallace $^{7}$ (2005) concluded that the apical preparation should be larger than that previously proposed by Kerekes and Tronstad ${ }^{5}$ (1977). ${ }^{5,7}$ However, to achieve a more accurate estimate of the apical diameter, removal of the interferences along the canal is necessary. ${ }^{8}$ If the canals are narrow or have interferences in the coronal two thirds, the clinician cannot accurately identify the apical anatomy. After coronary thirds enlargement, the quality of the tactile sensitivity improves the estimate of the apical 
diameter. ${ }^{8}$

In cases of pulp necrosis, in which the bacterial presence is inherent, disinfection of the canal as proposed by Weine ${ }^{6}$ (1989) allows for a higher reduction in the bacterial population..$^{6,9,10,11}$ A deeper penetration of the irrigation with a larger volume may facilitate this disinfection. ${ }^{9,12}$

With regard to fillings, Wu et al. ${ }^{2}$ (2000) and Weiger et al. ${ }^{13}$ (2006) confirmed that many of the canal areas (especially in the apical region) are not touched during canal preparation due to its oval or irregular configurations.

The aim of the present study was to determine the adaptation of the first apical file after preflaring in the mesiobuccal (MB) and mesiolingual (ML) canals of mandibular molars considering the tactile sensibility as a reference, using scanning electron microscopy.

\section{Material and Methods}

Twelve human mandibular molars, partially intact with no determined age and complete root formation, were selected for this study. All teeth presented moderate root canal curvature ( $>35$ degrees), according to the Schneider method. The teeth had been previously cleaned with periodontal curettes (Golgran, São Caetano do Sul, SP, Brazil) sterilized in an autoclave (Dabi Atlante; Ribeirão Preto, SP, Brazil) and stored in saline solution. Only the mesial roots, comprising a total of 22 canals (12 mesiobuccal and 10 mesiolingual) were used in this study.

The caries were removed with round diamond burs and the access to the root canals was performed using round steel burs \# 4 and \# 6 (KG Sorensen, São Paulo, Brazil) and the conic steel bur endo-Z (Dentsply Maillefer, Ballaigues, Switzerland) at high speed under water spray. After completing the access to the canals, canals were repeatedly irrigated and aspirated with $1 \%$ sodium hypochlorite for debris removal. The full working length was established by deducting $1 \mathrm{~mm}$ from the actual canal length, which had been determined by inserting a size 06 K-file (Dentsply Maillefer, Ballaigues, Switzerland) into the canal until the tip of the file was just visible at the apical foramen.
The cervical thirds of the canals were then flared with batt burs \#2 and \#4 (Dentsply Maillefer, Ballaigues, Switzerland) and Gates-Glidden \#2 and \#3 (Dentsply Maillefer, Ballaigues, Switzerland), under irrigation with $1 \%$ sodium hypochlorite. After preflaring, the canals were then crown-down prepared according to the following protocol: the \#45 (Dentsply Maillefer, Ballaigues, Switzerland) file was used to initiate the preparation (in all cases the \#45 file did not reach the working length). The \#45 file (Dentsply Maillefer, Ballaigues, Switzerland) was inserted to the point of the first resistance, and four balanced-force movements were performed without apical pressure. The \#45 file (Dentsply Maillefer, Ballaigues, Switzerland) was removed, and the canal was irrigated with $1 \%$ sodium hypochlorite. Next, the immediately smaller file (\#40, Dentsply Maillefer, Ballaigues, Switzerland)) was used to prepare the canal walls using the same technique. It was successively repeated until the working length was reached, such that the file that bound at the working length was the smallest one. The file diameter was recorded for both canals and the diameter of the first apical file was considered.

The first apical file was attached to the root with cyanoacrylate (SuperBonder-Loctite, São Paulo, Brazil), and the roots were then sectioned perpendicularly $1 \mathrm{~mm}$ from the apex with a $0.30-\mathrm{mm}$ thick diamond disk (KG Sorensen, São Paulo, SP, Brazil). The working length region was evaluated using a scanning electron microscope (Zeiss DSM 940A, Oberkochen, Germany) at $200 \mathrm{X}$ magnification. The images were recorded digitally and stored as TIFF (tagged image file format) files. Subsequently, the percentage of contact of the file with the canal (PCFC) at the apex region was obtained using Image J software (http://rsbweb.nih.gov/ij, National Institutes of Health, Bethesda, MD, USA). The software was calibrated according to the reference bar provided by scanning electronic microscopy. Finally, the canal perimeter was measured with the analyze tool. The same tool was used to obtain the percentage of file-to-canal contact.

Values obtained were tabulated using SPSS 8.0 software (SPSS Incorporated, Chicago, IL, USA). 


\section{Results}

The relationship between the perimeter of contact of the instrument bound at the apical region and the perimeter of the canal in the mesiobuccal and mesiolingual canals is expressed in Graph 1 and Tables 1 and 2. When the canals merged, the perimeter obtained was expressed as the sum of the areas of contact of the two files $(40.03 \%)$.

\section{Discussion}

This study was conducted on the mesial root of mandibular molars, where the canals have very small diameters. ${ }^{5,14}$ Tactile sensibility is an important parameter for the execution of several dental procedures; although subjective, tactile sensitivity is frequently used by experienced clinicians for the determination of the apical diameter in endodontics.

During root canal shaping, the anatomical diameter of the apical area is determined through the identification of the first file that, in the working length, finds resistance in the dentinal walls, and binds to them. ${ }^{15,16}$ Both the detection of apical constriction and the determination of instrument size are accomplished through the clinician's tactile sensibility. This approach is based on the supposition that the root canal is narrow at the apical third and that the file can pass without interference until the apical region.

The magnitude of apical shaping depends on the determination of the first file size that binds at the apical constriction, while the detection of this constriction is provided by tactile sensitivity. How-

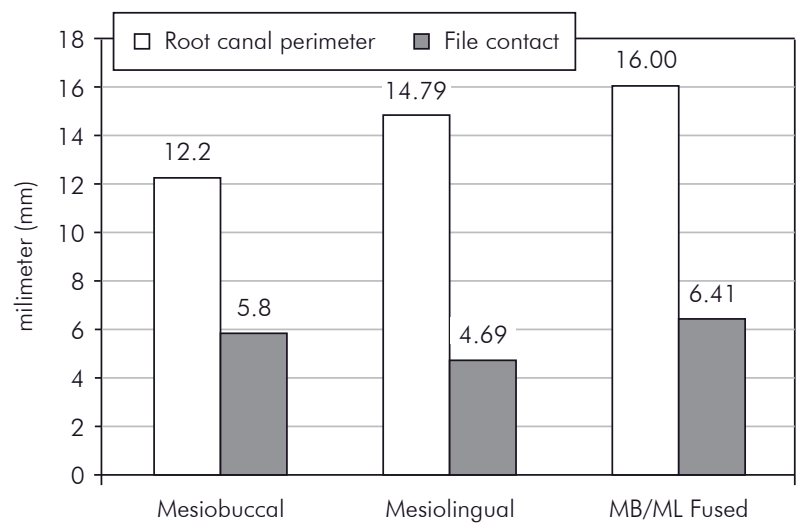

Graph 1 - Mean values of canal perimeter at the working length region and contact of the first apical file with the canal walls. ever, tactile sensitivity cannot be used to determine whether the instrument is bound at the constriction zone or at any other interference along the root canal. The tactile sensation of the apical constriction

Table 1 - Perimeter of the canal at the working length region $(\mathrm{mm})$ and contact of the first apical file to the canal walls $(\mathrm{mm})$, of each sample.

\begin{tabular}{|c|c|c|c|c|}
\hline Sample & Canal & $\begin{array}{c}\text { Canal } \\
\text { perimeter }(\mathrm{mm})\end{array}$ & $\begin{array}{l}\text { File contact } \\
(\mathrm{mm})\end{array}$ & $\begin{array}{l}\text { First Apical } \\
\text { file \#ISO }\end{array}$ \\
\hline \multirow{2}{*}{$1 \S$} & $M B$ & \multirow{2}{*}{5.0} & 1.248 & \#30 \\
\hline & $M L$ & & 1.006 & $\# 40$ \\
\hline \multirow{2}{*}{2} & $M B$ & 1.230 & 0.489 & \#25 \\
\hline & $M L$ & 0.971 & 0.508 & \#25 \\
\hline \multirow{2}{*}{3} & $M B$ & 1.490 & 0.595 & \#30 \\
\hline & $M L$ & 1.319 & 0.644 & \#30 \\
\hline \multirow{2}{*}{$4 \S$} & $M B$ & \multirow{2}{*}{2.506} & 0.577 & \#25 \\
\hline & $M L$ & & 0.611 & \#25 \\
\hline \multirow{2}{*}{5} & $M B$ & 2.930 & 0.918 & \#30 \\
\hline & $M L$ & 1.590 & 0.833 & \#30 \\
\hline \multirow{2}{*}{6} & $M B$ & 1.212 & 0.932 & \#30 \\
\hline & $M L$ & 2.964 & 1.129 & $\# 40$ \\
\hline \multirow{2}{*}{7} & $M B$ & 1.245 & 0.584 & \#25 \\
\hline & $M L$ & 1.377 & 0.701 & \#25 \\
\hline \multirow{2}{*}{8} & $M B$ & 1.924 & 0.934 & $\# 40$ \\
\hline & $M L$ & 6.569 & 0.876 & $\# 40$ \\
\hline \multirow{2}{*}{$9^{\S}$} & $M B$ & \multirow{2}{*}{3.395} & 0.520 & \#30 \\
\hline & $M L$ & & 0.838 & \#30 \\
\hline \multirow{2}{*}{$10^{\S}$} & $M B$ & \multirow{2}{*}{5.101} & 1.308 & \#35 \\
\hline & $M L$ & & 0.298 & $\# 40$ \\
\hline \multirow{2}{*}{11} & $M B$ & 1.328 & 0.860 & \#30 \\
\hline & - & - & - & - \\
\hline \multirow{2}{*}{12} & $M B$ & 0.860 & 0.533 & $\# 20$ \\
\hline & - & - & - & - \\
\hline
\end{tabular}

§Fused canals; - Absent canal; $M B=$ mesiobuccal; $M L=$ mesiolingual.

Table 2 - Contact (\%) of the first file to the canal walls at the apex (MB and ML canals).

\begin{tabular}{c|c|c}
\hline $\mathrm{MB}$ canal & $\mathrm{ML} / \mathrm{MB}$ canal & $\mathrm{ML}$ canal \\
\hline Individual foramen & foramen fused & Individual foramen \\
$47.83 \%$ & $40.03 \% *$ & $31.71 \%$ \\
\hline
\end{tabular}

* In cases of fused canals/foramens two files were used to determine the percentage of contact. The sum of the result (\%) for each file was considered the total contact in such cases. 
may be improved in cases where early preflaring has been performed..$^{14,17,18}$

Silveira et al. ${ }^{8}$ (2008) verified that the removal of anatomic interferences along the root canal made the estimate of the first file that binds at the apical region more precise. The diameter of the first apical file used following this procedure presented an increase of two diameters of instruments, when compared to samples without interference removal.

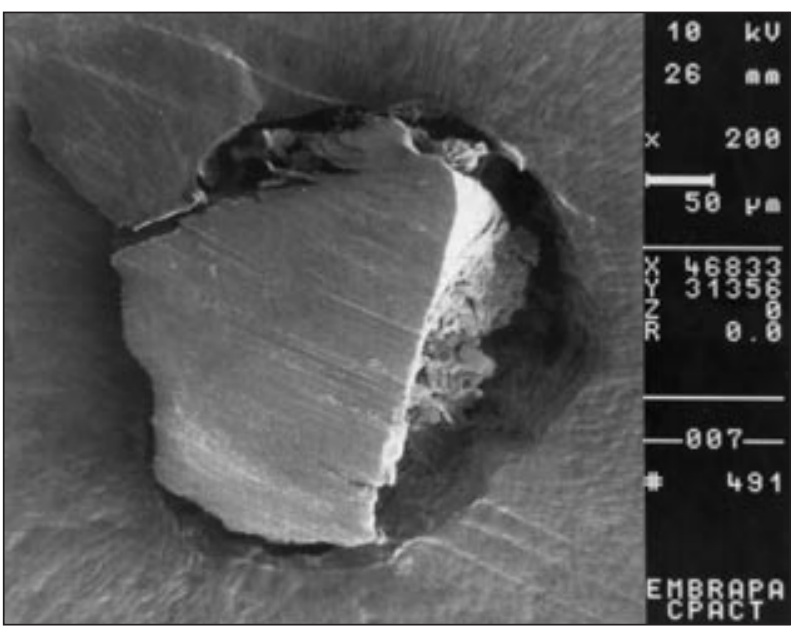

Figure 1 - Example of file adaptation on the dentin walls at $1 \mathrm{~mm}$ from the anatomic apex (original magnification $200 X)$

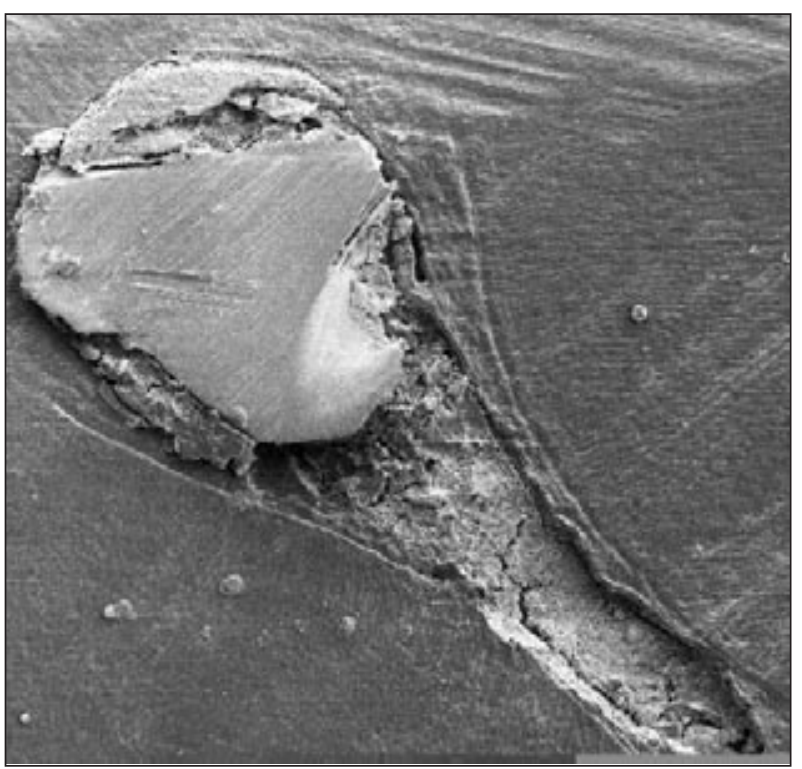

Figure 2 - Sample showing the incomplete contact of the apical file with the dentin walls of the anatomic apex (original magnification 200 X).
Tactile sensitivity determines the number of instruments necessary for the enlargement of the apical area. Therefore, the determination of the apical diameter, which according to current endodontic concepts has the same biological importance as the working length, is dependent on a procedure that is not objective and does not present scientific evidence to orient its clinical use. The present data reinforce that the clinical determination of the first apical file by tactile sensitivity, performed after the removal of interferences along the canal, promotes a contact area considered satisfactory for the objectives of endodontic therapy. The difficulties in adapting the files at the apical area are predominantly related to the anatomical form and are particularly related to the fusion of the mesial canals of the lower molar where the neighboring canal constitutes one of the canal walls.

The current findings indicate that the changes in root canal geometry after preparation are more dependent on the type of canal than on the technique or instruments used to shape the canals. ${ }^{19}$ If the apical region is round, the first file that binds in the working length will most likely wear the entire canal perimeter with three more file diameters. When this region is oval, however, the file will not simultaneously touch the whole diameter (Figures 1-3). Consequent-

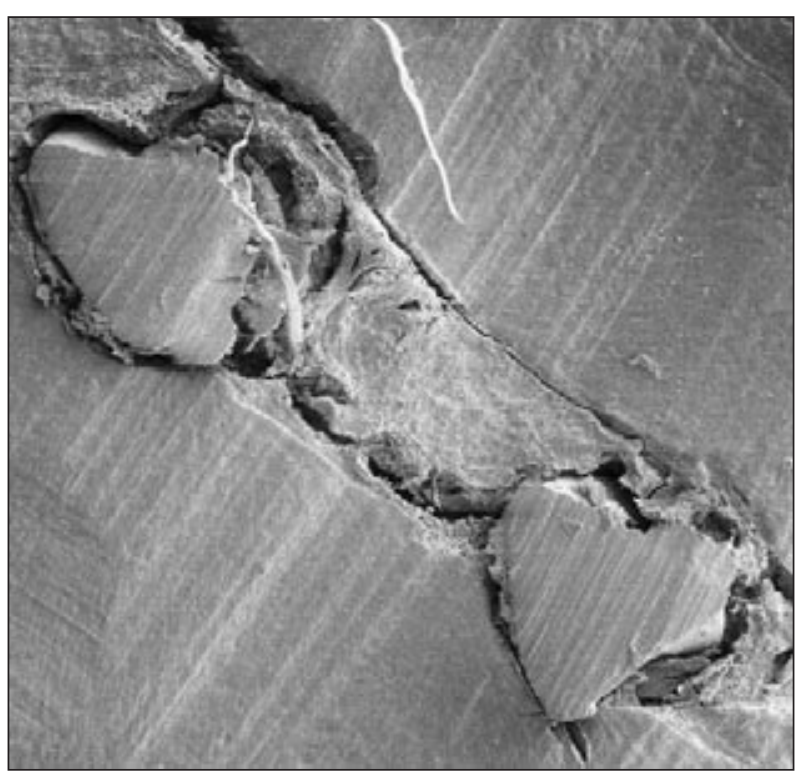

Figure 3 - Sample showing a case of fused canals/foramens and the two files used to determine the percentage of contact (original magnification $200 \mathrm{X}$ ). 
ly, the objective of removing the infected dentin layer and preventing the development or persistence of apical periodontitis might not be accomplished. ${ }^{20,21}$

The removal of interference from the root canal, as in this study, resulted in a level of contact with the walls of the canal in the apical third insufficient for the goals of endodontics. However, contact was achieved at around $40 \%$ of the apical areas. It is noteworthy that the apical anatomy interferes in a significant way with the goal of achieving contact with all walls.

\section{References}

1. Grande NM, Plotino G, Pecci R, Bedini R, Pameijer $\mathrm{CH}$, Somma F. Micro-computerized tomographic analysis of radicular and canal morphology of premolars with long oval canals. Oral Surg Oral Med Oral Pathol Oral Radiol Endod. 2008 Sep;106(3):e70-6.

2. Wu MK, R'oris A, Barkis D, Wesselink PR. Prevalence and extent of long oval canals in the apical third. Oral Surg Oral Med Oral Pathol Oral Radiol Endod. 2000 Jun;89(6):73943.

3. Wu MK, Wesselink PR. A primary observation on the preparation and obturation of oval canals. Int Endod J. 2001 Mar;34(2):137-41.

4. Martos J, Ferrer-Luque CM, González-Rodriguez MP, Castro LAS. Topographical evaluation of the major apical foramen in permanent human teeth. Int Endod J. 2009 Apr;42(4):329-34.

5. Kerekes K, Tronstad L. Morphometric observations on the root canals of human molars. J Endod. 1977 Mar;3(3):114-8.

6. Weine FS. Endodontic Therapy. St. Louis: Mosby; 1989. Intracanal treatment procedures, basic and advanced topics. p.256-369.

7. Baugh D, Wallace J. The role of apical instrumentation in root canal treatment: a review of the literature. J Endod. 2005 May;31(5):333-40.

8. Silveira LF, Martos J, Pintado LS, Teixeira RA, César Neto JB. Early flaring and crown-down shaping influences the first file bind to the canal apical third. Oral Surg Oral Med Oral Pathol Oral Radiol Endod. 2008 Aug;106(2):e99-101.

9. Siqueira JF Jr, Rôças IN, Santos SR, Lima KC, Magalhães FA, de Uzeda M. Efficacy of instrumentation techniques and irrigation regimens in reducing the bacterial population within root canals. J Endod. 2002 Mar; 28(3):181-4.

10. Card SJ, Sigurdsson A, Orstavik D, Trope M. The effectiveness of increased apical enlargement in reducing intracanal bacteria. J Endod. 2002 Nov;28(11):779-83.

11. Mickel A, Chogle S, Liddle J, Huffaker K, Jones JJ. The role of apical size determination and enlargement in the reduction of intracanal bacteria. J Endod. 2007 Jan;33(1):21-3.
New techniques and technologies should be developed with the objective of predicting in a more accurate manner the apical diameter for shaping. Such developments are fundamental for cleaning, disinfecting and filling the root canal and, consequently, for success in endodontics.

\section{Conclusion}

The technique employed in the present study did not allow the first apical file to touch all dentin walls of the apical region.

12. Vianna ME, Horz HP, Gomes BP, Conrads G. In vivo evaluation of microbial reduction after chemo-mechanical preparation of human root canals containing necrotic pulp tissue. Int Endod J. 2006 Jun; 39(6):484-92.

13. Weiger R, Bartha T, Kalwitzki M, Löst C. A clinical method to determine the optimal apical preparation size. Part I. Oral Surg Oral Med Oral Pathol Oral Radiol Endod. 2006 Nov;102(5):686-91.

14. Contreras MAL, Zinman EH, Kaplan SK. Comparison of the first file that fits at the apex, before and after early flaring. J Endod. 2001 Feb;27(2):113-6.

15. Grossman LI, Oliet S, Del Río CE. Endodontic Practice. $11^{\text {th }}$ ed. Philadelphia: Lea \& Febiger; 1988. Preparation of the root canal: equipment and technique for cleaning, shaping and irrigation. p.179-227.

16. Walton RE, Rivera EM. Cleaning and shaping. In: Walton RE, editor. Principles and Practice of Endodontics. Philadelphia: Saunders; 1996. p.201-233.

17. Seidberg BH, Alibrandi BV, Fine H, Logne B. Clinical investigation of measuring working lengths of root canals with an electronic device and with digital tactile sense. J Am Dent Assoc. 1975 Feb;90(2):379-87.

18. Stabholz A, Rotstein I, Torabinejad M. Effect of preflaring on tactile detection of the apical constriction. J Endod. 1995 Feb;21(2):92-4.

19. Peters OA, Laib A, Göhring TN Barbakow F. Changes in root canal geometry after preparation assessed by high-resolution computed tomography. J Endod. 2001 Jan;27(1):1-6.

20. Iqbal MK, Ku J. Instrumentation and obturation of the apical third of root canals: addressing the forgotten dimension. Compend Contin Educ Dent. 2007 Jun;28(6):314-20.

21. Oliveira LD, Carvalho CAT, Valera MC, Koga-Ito CY, Jorge AOC. Diffusion ability of endotoxin through dentinal tubules. Braz Oral Res. 2005 Jan-Mar;19(1):5-10. 